\title{
In The Same Focus Recurrent Proximal Tibial Osteoid Osteoma: A Case Report
}

\section{Tibia Proksimalinde Aynı Odakta Yeniden Gelişen Osteoid Osteom Olgusu: Olgu Sunumu}

\author{
Reşit Sevimli' ${ }^{1}$ Mahmut Kalem², Adem Ünlü², Kerem Başarır², Yavuz Yener Sağlık² \\ ${ }^{1}$ İnönü Üniversitesi Tıp Fakültesi, Ortopedi Ve Travmatoloji Ana Bilim Dalı, Malatya, Türkiye \\ ${ }^{2}$ Ankara Üniversitesi Tıp Fakültesi, Ortopedi Ve Travmatoloji Ana Bilim Dalı, Ankara
}

Doi: $10.5505 /$ aot.2013.55265

\section{ÖZET}

Osteoid osteom, nadir görülen benign kemik tümörlerindendir. Tedavide cerrahi nidus eksizyonunun sonuçları yüz güldürücüdür ve tedavi sonrası nüks oluşumu çok nadirdir. Bu yazıda tibia alt uçta eksizyon yapılan osteoid osteom olgusunun tedaviden 7 yıl sonra ortaya çıkan nüksü sunuldu.

Anahtar Kelimeler: Osteoid osteom; Tibia; Nüks

\begin{abstract}
Osteoid osteoma seen between a rare benign bone tumors; Although promising treatment relapse after treatment but is very rare in focus. At the upper end of the tibia 7 years after excision made the same focus new osteoid osteoma. Relapse cases were presented.
\end{abstract}

Key words: Osteoidosteoma; Tibia; Recurrence

\section{Giriş}

Osteoid osteom çoğunlukla çocuklarda ve genç erişkinlerde görülen, genellikle çapı 1-2 cm'den küçük iyi huylu kemik tümörüdür (1). Sıklıkla femur ve tibia yerleșimli olan bu tümör iyi damarlanmış ve değişik düzeylerde kalsifiye olmuş, küçük bir osteoid dokudan oluşan nidus ile karakterizedir (2). Çoğunlukla geceleri artan, özellikle aspirin ve diğer nonsteroid antienflamatuar ilaçlara (NSAİI) yanıt veren ağrı ile karakterizedir (3). Tanı; klinik, direkt radyografi, bilgisayarlı tomografi (BT), sintigrafi ve histopatolojik inceleme ile konur (4). Klasik tedavisi nidusun total eksizyonu olup, rezidü kalan nidus şikayetlerin devamına yol açar. Bu çalışmada tibia üst uçta yerleşimli osteoid osteoma olgusunda eksizyon sonrası kliniğin tamamen kaybolduğu izlenen ancak 7 yıl sonra aynı odakta yineleyen osteoid osteomaya ait tanı ve tedavi sonucu sunuldu.

\section{Olgu sunumu}

Onbir yaşında kız hasta ilk olarak yaklaşık 1 yıldır sol dizde ağrı şikayeti ile başvurmuş. İlk başvuruda büyüme ağrıları olarak değerlendirilmiş ve yatak istirahatı ile konservatif tedavi önerilmiş. Takiplerinde hastanın ağrı şikayetin artan vasıfta olması üzerine kliniğimize yönlendirilmiş.

Sol diz ağrısının devamlılık gösterdiği ve özellikle geceleri daha belirgin, uykudan uyaran karakterde olduğu ve tipik olarak aspirin kullanmakla azaldığ anamnezinde mevcuttu. Hastanın sol diz ön arka (AP) grafisinde tibia üst uç anteromedial bölgede, lateral grafide ise anterior kortekse yakın yerleşimli lezyon saptand $($ Resim 1a,b). Hastanın kan tablosunda önemli bir özellik görülmedi. BT incelemesinde lezyonun $1 \mathrm{x} 1 \mathrm{~cm}$ boyutlarında, ortası sklerotik, çevresi radyolusen olduğu ve en dişta bu yapıyı çevreleyen kemik dokuda sklerozun bulunduğu gözlendi ve osteoid osteom ile uyumlu olarak değerlendirildi. (Resim 2). Manyetik rezonans görüntüleme (MRG) ile değerlendirmede, tibia üst uçta çevre yumuşak dokuda yaygın ödem ile birlikte lezyonun osteoid osteom ile uyumlu olduğu teyit edildi. BT ve MR bulgular1 hastanın kliniği ile birlikte değerlendirildiğinde osteoid osteom ile uyumlu olan lezyon için 2008 yılinda en blok eksizyon yapild 1 Sklerotik alan eksize edildi. Patoloji sonucu 
osteoid osteom ile uyumlu gelen hastanın şikayetlerinin ameliyat sonrası ilk günden itibaren kaybolduğu görüldü. Ameliyat sonrası grafisinde nidus içeren radiolusent alanın sklerotik kemikle beraber çıkartılmış olduğu görüldü (Resim 3). Ameliyat sonrası hastanın 7 yıllık takiplerinde şikayeti olmadı. Mayıs 2014 tarihinde ameliyat lokalizasyonunda tekrar ağrıları başlayan hastanın ağrısının gece ortaya çıkan ve aspirine cevap veren vasıfta olduğu görüldü. Hastanın direk grafi ve BT incelemelerinde eski operasyon alanında nidus içeren, osteoid osteoma'ya benzer görüntü izlendi (Resim 4a,b-5). Hastada aynı bölgeye tekrar cerrahi eksizyon yapıldı. (Resim 6a,b). Patoloji osteoid osteom ile uyumlu idi. Ameliyat sonrası hastanın şikayetlerinin tamamen kaybolduğu görüldü.

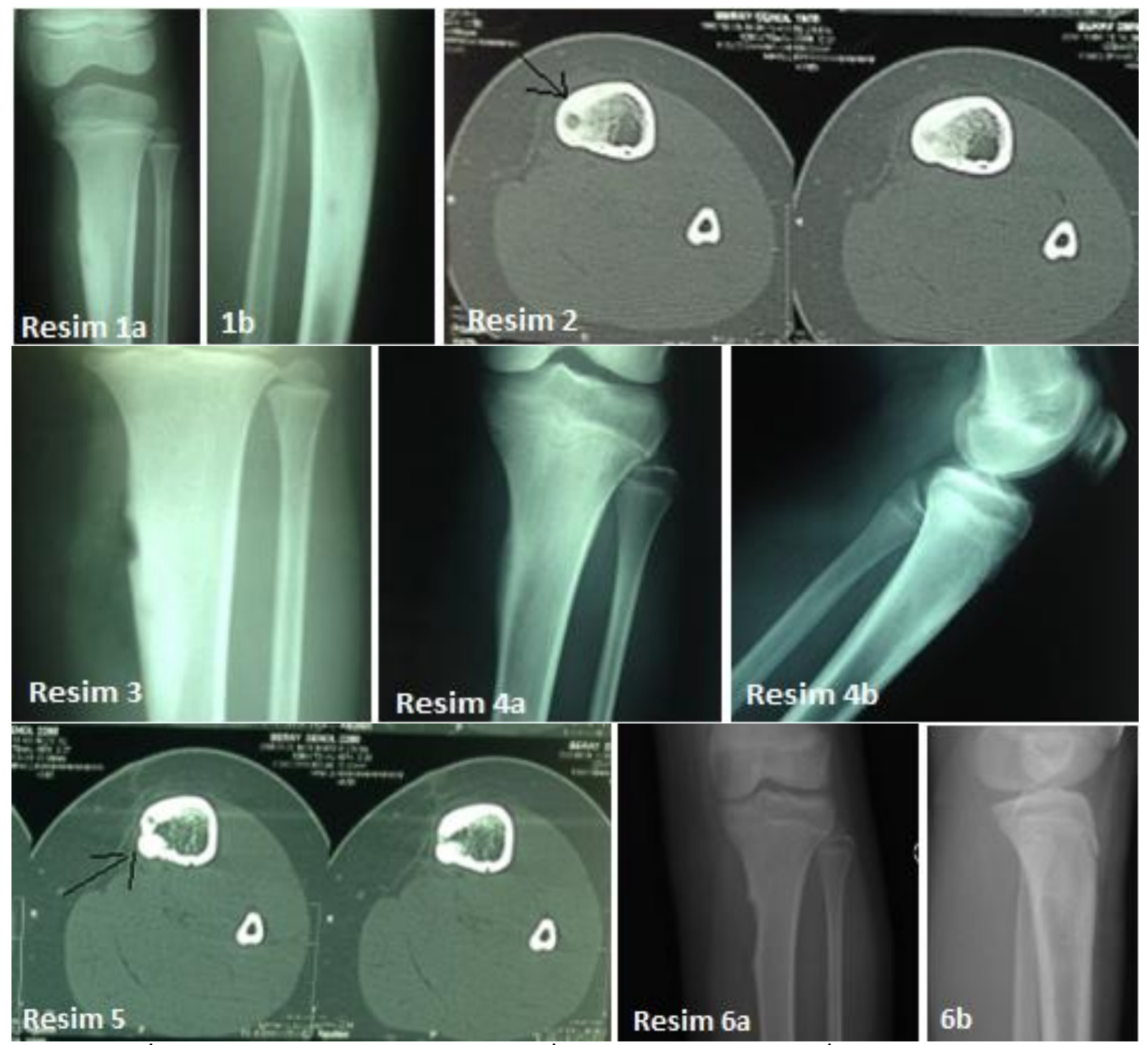

Resim 1a,b: İlk ameliyat öncesi AP-Lateralgrafi, 2: İlk ameliyat öncesi BT, 3: İlk ameliyat sonrası AP grafisi, 4a,b: İkinci ameliyat öncesi AP-Lateralgrafi, 5: İkinci ameliyat öncesi BT, 6a,b: İkinci (son) ameliyat sonrası AP-Lateralgrafi

\section{Tartışma}

Osteoid osteom tüm kemik selim tümörleri içerisinde \%10 sıklıkta izlenen, osteoblastik özellikte bir lezyonudur $(4,5)$. Femur ve tibia en sık görüldüğü lokalizasyonlardandır (4). Erkeklerde kadınlara oranla 2-3 kat daha fazla görülür (5). Osteoid osteom daha çok uzun kemiklerin diyafiz ve metafizer bölgelerine yerleşir. Kemikteki yerleşimleri ise sıklıkla intrakortikaldir (4). İntrakortikal yerleşimli olanlarda nidus radyolusen olarak görülür ve nidus çap 1 cm'yi genellikle geçmez, ama 2 cm'ye kadar büyük çapta da olabilir (5).

İntraoperatif nidusun yerinin belirlenmesi cerrahi girişimin başarısı için şarttır. 
Direk grafiler, BT, çeşitli kimyasal işaretlemeler ve kemik sintigrafisi bu amaç için kullanılır (6). MRG ise genellikle osteoid osteoma eşlik eden yumuşak doku ve kemik iliği ödemini ortaya koymada anlamlıdır $(4,6)$.

Nidusun total çıkarılması veya koterizasyonu sonrası nüks genellikle çok nadir görülür. İlk defa 1970 y1lında Dunlop, Morton ve Elliott tarafindan dile getirilmiş ve 1975 y1lında Worland ve ark. bir olgu sunumu yayınlamışlardır $(2,7,8)$. Dunlop ve ark. yayınladıkları nüks olgusunda sonucu yetersiz eksizyona bağlamışlardır (7). Worland ve ark. ise tam eksizyona rağmen olgularında 1 yıl sonra nüks geliştiğini belirtmişlerdir (2). Bunu da tespit edilemeyen satellit bir odağa yada aynı koşullarda yeni bir lezyon oluşumuna bağlamışlardır.

Bizim olgumuzda da Worland ve ark.'nın olgusuna benzer şekilde tam eksizyon yapılmasına rağmen aynı zeminde görülen osteoid osteom olgusuydu. Olgumuzun ilk ameliyatta total eksizyon sonrası şikayetlerinin tamamen kaybolmasi, ve 7 yil sonra tekrarlamas1 lezyonun muhtemel satellit odak ihtimalini azaltmaktadır. $\mathrm{Bu}$ bağlamda aynı odakta yeni bir lezyon oluşumu öngörülebilir. Dolayısıyla olgunun aynı odakta ikinci primer osteoid osteoma gelişimi açısından literatüre önemli bir katkı sunacağı kanaatindeyiz.

Sonuç olarak, osteoid osteoml olgularda, nidus sahasının cerrahi sırasında tam olarak tesbit edilip, nidusun tamamen çıkarılması, nüksü engellemekte ve başarılı bir sonuç almayı sağlamaktadır, fakat tam nidus eksizyonu yapılan ve aynı yerde ağrısı olan hastalarda aynı lokalizasyonda yeni bir lezyon ihtimali akıldan çıkarılmamalıdır.

\section{Çıkar Çatışması: Yok}

\section{Kaynaklar}

1. Ofluoğlu Ö, Erol B, Mik G, et al. Uzun kemik yerleşimli osteoid osteomada görüntüleme yardımlı minimal invaziv cerrahi. Acta Orthop Traumatol Turc 2006;40:207-13

2. Worland RL, Ryder CT, Johnston AD. Recurrent osteoid osteoma. Report of a case. J Bone Joint Surg Am. 1975;57:277-8

3. Aynacı O, Şener M, Aydın H, et al. Proksimal femur yerleşimli osteoid osteomalar (on iki olgunun değerlendirilmesi). Acta Orthop Traumatol Turc 2001;35:95-8

4. Jaffe HL. Osteoid osteoma of bone. Radiology 1945;45:319-34

5. Campanacci M. Bone and sof ttissue tumors. New York:Springer-Verlag;1990.p.355-73

6. Jennin F, Bousson V, Parlier C, et al. Bony sequestrum: a radiologic review. Skeletal Radiol 2011;40:963-75

7. Dunlop JAY, Morton KS, Elliott GB. Recurrent osteoid osteoma: Report of case with a review of the literature. J Bone Joint Surg Br 1970;52:128-33

8. Yang JH, Park JH, Min KW, et al. Post-traumatic extra-articular osteoid osteoma of The calcaneus following military training. J Orthop Sci 2011;16:326-8 